\title{
Malicious Email Tracking System for Prevention of Malicious Code Delivered via Email
}

\author{
A.StephenAntoJegan ${ }^{1}$, Dr. K.P.Kaliyamurthie ${ }^{2}$, Dr.M.Sriram ${ }^{3}$ \\ \{stephen_jegan@yahoo.co.in ${ }^{1}$, kpkaliyamurthie@gmail.com², msr1sriram@gmail.com ${ }^{3}$ \} \\ Research Scholar, Department of CSE, Bharath Institute of Higher Education and Research, \\ Chennai ${ }^{1}$, Professor, Department of CSE, Bharath Institute of Higher Education and Research, Chennai ${ }^{2}$, \\ Associate Professor, Department of CSE, Bharath Institute of Higher Education and Research, Chennai ${ }^{3}$
}

\begin{abstract}
Despite the use of state of the artwork strategies to shield touching malicious packages, they maintain to threaten and damage pc structures around the arena. In this articles we existent MET, the Malicious Email Tracking device, designed to mechanically file records on the movement conduct of malicious software distributed through e-mail attachment together at a global and local degree. MET can assist decreasethe unfold of malicious software global, specially self-replicating viruses. Small quantity of site visitors (as an example, $.1 \%$ ) of a completely massive e-mail circulation is sufficient to come across suspicious. Consequently, moderately few MET connections would be vital to acquire enough information so that you can offer vast protection services.
\end{abstract}

Keywords: Malicious Email Tracking System MET, Malicious Code, Email.

\section{Introduction}

PC frameworks are continually enduring an onslaught by malignant programming joined to email. Email is liable for the blowout of $80 \%$ of PC infection. The most famous way to deal with safeguard against noxious programming is through enemy of infection scanners like Symantec and McAfee, just as worker based channels that channels email with executable attachments. These approaches have been fruitful in securing PCs against known pernicious projects However, they have not yet given a methods for ensuring against recently dispatched (obscure) viruses. Only as of late have there been ways to deal with recognize new or obscure vindictive programming by investigating the payload of an attachment. In ongoing years, not just have PC infections expanded drastically in number and started to show up in new and more unpredictable structures, yet the expanded between network of PCs has exacerbated the issue by giving the methods for quick popular proliferation. Since vindictive programming can not generally be identified ahead of time by investigating payload, we can lessen the harm brought about by malevolent programming by checking its conduct in spreading among hubs in networks[5]. 


\section{Existing System}

At present observing frameworks exist through associations like WildList, Trend Micro World Virus Tracking Center. WildList does exclude those situations where a connection is considered dubious however not yet named malignant. This leaves PC frameworks powerless against assault from unreported viral incidents. Since the way toward detailing isn't computerized, vindictive programming can spread a lot quicker than admonitions created by WildList. Pattern's information is inadequate. Besides, if Trend's information base isn't refreshed at the time that an infection contaminates a framework, at that point the infection stays unreported [6].

\section{Proposed System}

In these articles, we extant the MET framework tends to issues. The key diaerence among MET and past checking frameworks, for example, Trend is that MET concentrates and logs a special identifier from the connections going through a shopping center worker. In the event that a connection is found to be pernicious afterward, the insights on its practices will have been recorded and accessible for additional investigation and announcing capacities. MET gives three significant, abilities. The primary capacity is the capacity to follow the worldwide spread of malignant programming through email. The subsequent ability is deciding the entirety of the marks of passage through email of malevolent programming into an organization. This can help the framework heads contain the harm brought about by the software[7]. The third capacity is to decrease the feast of self-reproducing infections through email,.

\section{Unique Identifiers For Email Attachments}

The way to following connections MET framework is the task of an extraordinary identifier email connection. MET customer removes a connection from an email and figures an identifier from the payload of the connection. This interesting identifier is utilized to total data about a similar connection proliferated in dlaerent messages.

\section{MET Client}

The MET customer comprises of a few parts. The center of the MET customer is a data set, which stores data pretty much all emall connections that go through the mail worker. The MET framework contains a segment to incorporate with the shopping center cut off. In our model execution, we coordinated the MET customer with send letters utilizing procmail. The MET customer likewise contain a segment to register the extraordinary identifiers for connections. An information investigation part extricates insights from the data set to answer to the MET worker and a correspondence segment handle the correspondence among the MET customer and the MET worker. Regardless of whether a logged connection was not at first recognized as vindictive however simply later sorted to be in this way, the places of passage 
can in any case be recuperated since a record of all connections is put away in the information base.

\section{MET Client Architecture}

While checking the progression, all things considered, MET permits the framework executive to recognize email traffic covering non-malignant email influences and email traffic containing malevolent programming connections. These diaerences may turn out to be more obvious as all email is checked, and (transient) measurements are assembled cautiously inside that climate to build up standards for email streams.

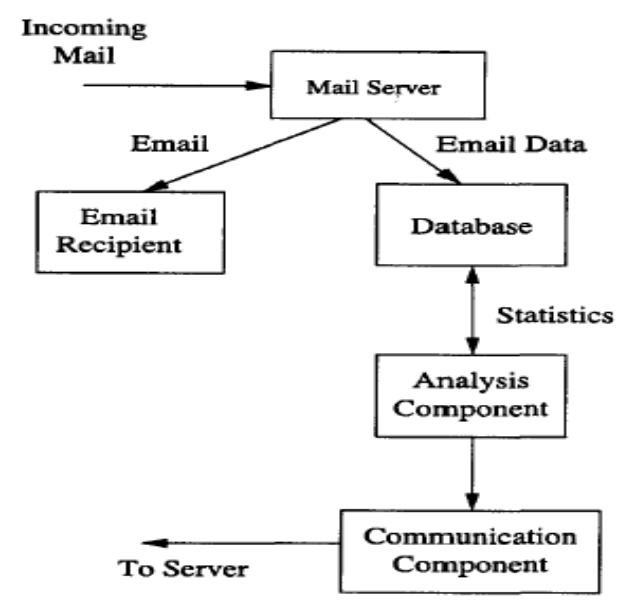

Figure1 MET Architecture

Each MET customer is needed to retain the base measure of data regardingemail that contains connections depicted in Table 1. Also, in the information base we stock the rundown of one of a kind identifiers for known malignant connections alongside the names of these attachments.Since MET can decide the marks of section of a vindictive connection into an organization, this can extraordinarily help the infection occurrence and the framework aclminlstraftor to decrease and contains the related harm. 


\begin{tabular}{|l|}
\hline Email Attachment Log Record: \\
\hline Unique ID of every Attachment \\
Time Stamp \\
Attachment Classification (Malicious or enign) \\
Sender Email \\
Receiver Email \\
\hline
\end{tabular}

Table 1: Information stored in MET Client

Database for each email that contains an attachment

\begin{tabular}{|l|}
\hline Record reporting malicious attachment incident \\
\hline ID of reporting server \\
Unique ID of attachment \\
Date/Time of report \\
revalence \\
irth Rate \\
\hline
\end{tabular}

Table 2: Information store on a central repository

The predominance is the occasions it was seen by the MET customer and the rate of birth is the normal number of duplicates sent from a similar client. Oth of these insights can be handily acquired from the information base. In segment 3 we show how we consolidate this data from different MET customers to measure the danger level and different insights on an infection from this essential data

\section{MET Server}

The MET worker run at a focal area and speaks with the MET customers conveyed at different mail workers. The MET worker can ordinarily be worked by a believed outsider and different organizations can settle on concurrences with this outsider to give the MET facility.The MET worker has a few capacities. The MET worker is answerable for spreading a refreshed rundown of special identifiers related with known vindictive infections to the MET customers. We bring up that the sort of data shipped off the MET worker are insights that secure the protection of separate clients who might have directed or gotten the malevolent connection. 


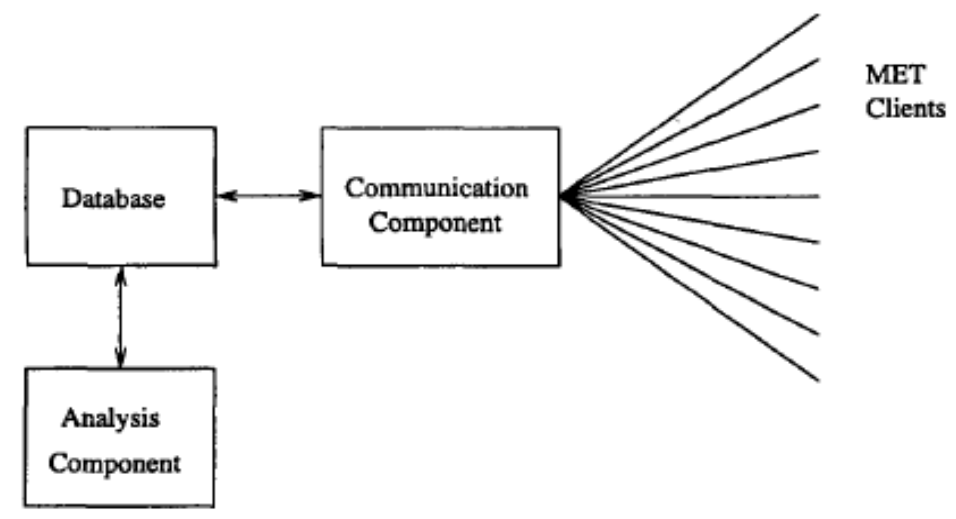

Figure 2. MET Server

\section{Conclusion}

Indeed, even with the utilization of cutting edge against infection programming, pernicious projects keep on making harm PC frameworks around the world. The Malicious Email Tracking framework was intended to assemble this data related to any enemy of infection scanners, and across has while keeping up protection and security policies. However, as the quantity of members expands, the measure of information acquired increases. The MET framework relies on the clients faith of the mail provider. The MET framework gathers and supplies data that is as of now gathered and put away by the mail worker. One benefit to this methodology is that we can measure the danger related with permitting the conveyance of the connection. This can permit managers of individual MET customers to put together their choice with respect to whether they ought to permit the emails to be conveyed dependent on this danger evaluation.

\section{References}

[1] B. Balzer. Assuring the safety of opening email attachments.

[2] HouseCall. Free online virus scan. Online Publication,2002. http://housecall.antivirus.com.

[3] D. M. C. Jeffrey O. Kephart and S. R. White.Computers and epidemiology. IEEE Spectrum. http://www.research.ibm.com/antivirns/SciArticless/Kephar

[4] Thomas C.Schmidt, Multimedia networking communication protocols- tschmidt@ieee.org

[5] Darren. L. Spohn, Data network design, TMH publications

[6] Daniel Minoli\& Emma Minoli, Delivering Voice Over IP networks, Wiley Computer publishing.

[7] Dr. Kaliyamurthie K.P "An Application Of Non-Uniform Cellular Automata For Efficient Cryptography” ,Indian Journal of Science and Technology, Vol 6, Issue 5S, page 4648-4652 May 2013.

[8] Dr. Kaliyamurthie K.P "K-Anonymity Based Privacy Preserving For Data Collection In Wireless Sensor Networks", Indian Journal of Science and Technology, Vol 6, Issue 5S, page 4604-4614 May 2013. 
[9] Dr. Kaliyamurthie K.P "Highly Secured Online Voting System Over Network", Indian Journal of Science and Technology, Vol 6, Issue 6S page 4831-4836 May 2013.

[10] Dr. Kumaravel. A "Vehnode: Wireless Sensor Network Platform For Automobile Pollution Control" IEEE explore, Vol Page(s): 963 - 966, 2013.

[11] Dr. Kumaravel. A "Multi- Classification Approach For Detecting Network" IEEE explore, Page(s): 1114 -1117,April 2013.

[12] T. Vijayan, M. Sangeetha, A. Kumaravel \& B. Karthik (2020): FeatureSelection for Simple Color Histogram Filter based on Retinal Fundus Images for DiabeticRetinopathy Recognition, IETE Journal of Research, DOI: 10.1080/03772063.2020.1844082.

[13] D. S. Vijayan, A. Leema Rose, S. Arvindan, J. Revathy, C. Amuthadevi, “Automation systems in smart buildings: a review", Journal of Ambient Intelligence and Humanized Computing https://doi.org/10.1007/s12652-020-02666-9

[14] Vijayan T, Sangeetha M, A. Kumaravel, Karthik B, "Gabor filter and machine learning based diabetic retinopathy analysis and detection", Microprocessors and Microsystems,2020. https://doi.org/10.1016/j.micpro.2020.103353.

[15] Vijayan T, SangeethaM, Karthik B, "Trainable WEKA Segmentation of Retinal Fundus Images for Global Eye Disease Diagnosis Application," International Journal of Emerging Trends in Engineering Research,Vol 8, No.9, pp. 5750-5754, Sep 2020. https://doi.org/10.30534/ijeter/2020/136892020

[16] C. Amuthadevi, D. S. Vijayan, Varatharajan Ramachandran, "Development of air quality monitoring (AQM) models using different machine learning approaches", Journal of Ambient Intelligence and Humanized Computing, https://doi.org/10.1007/s12652-020-02724-2

[17] Vijayan T, Sangeetha M, A. Kumaravel, Karthik B, "Fine Tuned VGG19 Convolutional Neural Network Architecture for Diabetic Retinopathy Diagnosis," Indian Journal of Computer Science and Engineering (IJCSE), Vol. 11, No. 5, pp. 615-622 Sep-Oct 2020. DOI: 10.21817/indjcse/2020/v11i5/201105266.

[18] Vijayan T, Sangeetha M, Karthik B, "Efficient Analysis of Diabetic Retinopathy on Retinal Fundus Images using Deep Learning Techniques with Inception V3 Architecture,” Journal of Green Engineering, Vol 10, Issue 10, pp. 9615-9625. Oct 2020 